\title{
MASALAH PENYIMPANAN CALSIUM OKSIDA DI GUDANG PT.SIBELCO BHUMIADYA
}

\author{
Achmad Fatkhurrozi ${ }^{1}$, Dewi Patonah ${ }^{2}$, Jamari Machmudin ${ }^{3}$ \\ Program Studi Teknik Industri ${ }^{1,2,3}$ \\ Universitas Widyatama \\ Jl CIkutra no 204A, Kota Bandung \\ achmad.fatkhurrozi020397@gmail.com ${ }^{1}$
}

\begin{abstract}
Abstrak
Proses penyimpanan Kalsium Oksida di Gudang cenderung merusak kualitas, di karenakan sifat Kalsium Oksida yang rentan terkena udara bebas, sehingga harus di analisa kembali fentilasi udara di dalam Gudang, jenis packing yang di gunakan dan sistem barang masuk dan barang keluar. Dari data pengamatan gudang PT.SIBELCO Bhumiadya di dapat beberpa kesalahan desain gudang, tata cara penyimpanan produk dan sistem keluar masuk yang haus di perbaiki
\end{abstract}

Kata Kunci:

Calsium Oksida, Gudang, Fentilasi

\begin{abstract}
The process of storing Calcium Oxide in the Warehouse tends to damage the quality, due to the nature of Calcium Oxide which is susceptible to free air, so it must be re-analyzed the air fentilation in the warehouse, the type of packing used and the system of incoming and outgoing goods. From the observation data of PT. SIBELCO Bhumiadya's warehouse it was able to find a number of warehouse design errors, procedures for storing products and a system of entry and exit that had to be repaired
\end{abstract}

Keywords:

\section{Calcium Oxide, Warehouse, Ventilation}

\section{Pendahuluan}

Gudang merupakan komponen penting dari rantai pasokan modern. Rantai pasokan melibatkan kegiatan dalam berbagai tahap: sourcing, produksi, dan distribusi barang, dari penanganan bahan baku dan barang dalam proses hingga produk jadi.
Gudang berfungi untuk melindungi bahan baku, bahan setengah jadi dan produk jadi, Peran gudang sangat penting bagi perusahaan untuk tempat menyimpan dan menjaga produk dari kerusakan.

PT.SIBELCO Bhumiadya merupakan salah satu unit usaha dari PT.SIBELCO (SIBELCO GROUP) yang bergerak dalam bidang pertambangan mineral, PT.SIBELCO Bhumiadya merupakan pabrik dan pertambangan Calsiun Oksida terbesar di Indonesia.

Kondisi yang saat ini terjadi adalah penyimpanan produk Calsium Oksida yang baik sehingga terjadinya penurunan kualitas dalam produk di setiap periode nya. Perusahaan tidak memperhitungkan dampak dari terjadinya penurunan kualitas akibat tidak adanya standar penyimpanan, standar packing dan pengaturan produk yang di dahulukan untuk keluar.

Sesuai dengan fungsi dari gudang maka harus di lakukan nya sebuah kajian tentang penyimpanan di PT.SIBELCO Bhumiadya adapun kenyataan masalah di lapangan adalah :

1. Desain gudang penyimpanan yang kurang cocok untuk Calsium Oxida

2. Desain packing yang di gunakan kurang coco untuk Calsium Oxida

3. Sistem keluar masuk barang yang kurang di perhatikan

\section{KAJIAN LITERATUR}

Gudang merupakan fasilitas khusus yang bersifat tetap, yang dirancang untuk mencapai target tingkat pelayanan dengan total biaya yang paling rendah. Gudang pada dasarnya adalah bangunan yang secara fisik mempunyai kriteria tertentu sebagai tempat penyimpanan barang, yang mana di dalamnya 
terdapat proses pergudangan (warehousing) berupa storage dan material handling.

Gudang adalah ruangan yang tidak bergerak yang dapat ditutup dengan tujuan tidak untuk dikunjungi untuk umum, melainkan untuk dipakai khusus sebagai tempat barang (Perpu Nomor 5 Tahun 1962)

gudang (kata benda) adalah bangunan yang dipergunakan untuk penyimpan barang dagangan. Pergudangan (kata kerja) adalah kegiatan menyimpan dalam gudang (John Warman 2004)

Gudang adalah ruangan untuk menyimpan barang yang berdinding, beratap dan terkunci.( Ibnu syamsi 1997 : 28) mengatakan bahwa gudang dapat digambarkan sebagai suatu sistem logistik dari perusahaan yang berfungsi untuk menyimpan produk dan erlengkapan produksi lainnya (bahan baku, goodin-process, barang jadi, spareparts, supplies dan dead stock) dan menyediakan informasi status kondisi material/produk yang disimpan di gudang sehingga informasi tersebut mudah diakses oleh siapapun yang berkepentingan dan selalu up-to-date. gudang mempunyai peran penting guna mendukung keberhasilan perusahaan dalam mencapai tujuannya. (Donal J. Bowersox Managemen Logistik, Tahun 2000)

Beberapa faktor yang perlu dipertimbangkan dalam menentukan besar kapasitas gudang antara lain:

1. Besar ukuran dari masing-masing barang yang hendak disimpan. Semakin besar ukuran barang akan memerlukan ruang yang sangat besar.

2. Waktu tenggang (lead time) dari pemesanan barang, jika waktu tenggang lebih cepat maka ruang penyimpanan harus semakin besar.

3. Jumlah atau banyaknya barang yang harus disimpan dan frekuensi keluar masuknya barang.

4. Faktor yang hendak diambil oleh pihak manajemen gudang yang meliputi faktor kehabisan barang, faktor kekurangan tempat penyimpanan pada saat barang tiba di gudang.

Selain ditentukan oleh besar ruangan, kapasitas gudang juga ditentukan oleh cara mengatur letak barang yang disimpan (layout ruang gudang). Gudang dengan tata ruang sembarangan dan berserakan tentunya kurang efisien dibandingkan dengan gudang yang tata ruangnya diatur dengan rapi. Selain hal tersebut diatas, terdapat hal lain yang harus diperhatikan, yaitu jenis barang yang disimpan apakah barang tersebut termasuk:

1. Fast moving, yaitu barang sirkulasinya cepat, biasanya berupa barang-barang yang laku cepat.

2. Slow moving, yaitu barang yang sirkulasinya lambat, biasanya berupabarang-barang yang lakunya lambat. Berdasarkan arus keluar masuk barang, terdapat beberapa bentuk layout gudang yang dapat diterapkan, yaitu:

a. Arus garis lurus sederhana Dengan menggunakan layout arus garis lurus sederhana arus barang akan berbentuk garis lurus. Lokasi barang yang akan disimpan dibedakan antara barang yang bersifat fast moving dan slow moving. Barang yang bersifat fast moving disimpan dilokasi yang dekat pintu keluar, sebaiknya barang yang bersifat slow moving disimpan dilokasi yang dekat pintu masuk. Arus garis lurus sederhana adalah seperti pada gambar berikut:

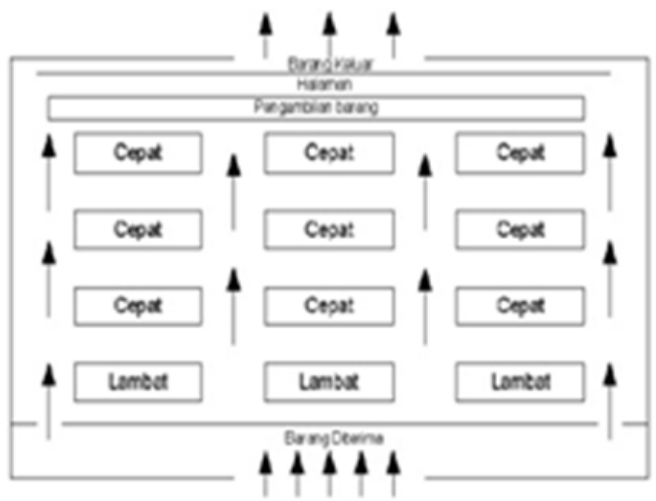

Gambar 1 Arus gudang lurus

b. Arus 'U'. Dengan menggunakan layout arus ' $u$ ' arus barang berbentuk 'U'. Barang yang bersifat fast moving disimpan dilokasi yang dekat dengan pintu keluar, sebaliknya barang yang bersifat slow moving disimpan dilokasi yang dekat dengan pintu masuk. Layout ' $u$ ' adalah seperti pada gambar berikut : 


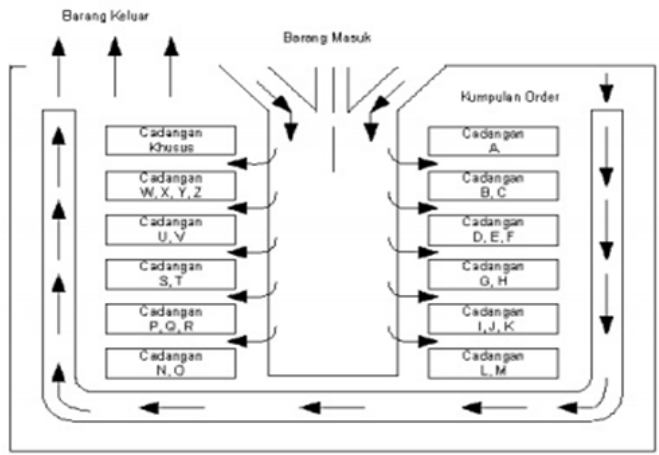

Gambar 2 Arus gudang $U$

c. Arus L . engan menggunakan layout ' $L$ ' arus barang berbentuk ' $L$ '.. Barang yang berssifat fast moving disimpan dilokasi yang dekat dengan pintu keluar, sebaliknya barang yang bersifat slow moving disimpan dilokasi yang dekat dengan pintu masuk. Layout dengan Arus ' $L$ ' adalah seperti pada gambar berikut:

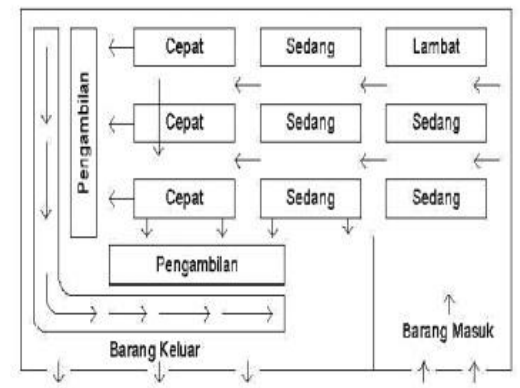

Gambar II.3 Arus gudang L

Kalsium Oksida, secara umum dikenal sebagai kapur mentah atau kapur bakar, adalah senyawa kimia yang digunakan secara luas. Kalsium Oksida merupakan kristal basa, kaustik, zat padat putih pada suhu kamar. Istilah yang luas digunakan "kapur" berkonotasi bahan anorganik yang mengandung kalsium, yang meliputi karbonat, oksida dan hidroksida kalsium, silikon, magnesium, aluminium, dan besi mendominasi, seperti batu gamping. Sebaliknya, "kapurmentah" khusus berlaku untuk senyawa kimia tunggal.

Kapur mentah harganya relatif murah. Keduanya dan turunan kimia (Calsium Hidroksida, yang mana kapur mentah anhidrida basa) adalah zat kimia komoditas penting.
Nama IUPAC kapur tohor ialah Calsium Oksida, nama lainnya Kapur mentah, kapur bakar, kapur tohor. Adapun sifat-sifatnya adalah:

Rumus molekul: $\mathrm{CaO}$

Berat molekul: 56,0774 gr/mol

Penampilan: Serbuk putih sampai kuning pucat/coklat

Bau: Tidak berbau

Densitas: 3,34 gr/cm3

Titik lebur: $2613{ }^{\circ} \mathrm{C}, 2886 \mathrm{~K}, 4735^{\circ} \mathrm{F}$

Titik didih: $2850{ }^{\circ} \mathrm{C}, 3123 \mathrm{~K}(100 \mathrm{hPa})$

Kelarutan dalam air: $1,19 \mathrm{~g} / \mathrm{L}\left(25{ }^{\circ} \mathrm{C}\right) ; 0,57 \mathrm{~g} / \mathrm{L}(100$ $\left.{ }^{\circ} \mathrm{C}\right)$; reaksi eksoterm

Kelarutan dalam asam: Larut (juga dalam gliserol, larutan gula)

Kelarutan dalam methanol: Tidak larut (juga dalam dietil eter, n-oktanol)

Keasaman (pKa): 12,8

Entropi molar standar So298: $40 \mathrm{~J} \cdot \mathrm{mol}-1 \cdot \mathrm{K}-1$

Entalpi pembentukan standar $\Delta \mathrm{fHo298}: \quad-635$ $\mathrm{kJ} \cdot \mathrm{mol}-1$

Titik nyala: Tidak terbakar

Calsium Oksida biasanya dibuat melalui dekomposisi termal bahan-bahan seperti batu gamping (limestone), atau cangkang kerang (atau cangkang molluska lainnya), yang mengandung Calsium Carbonat (CaCO3; mineral kalsit) sebagai kapur bakar (lime kiln). Hal ini dilakukan dengan memanaskan material ini di atas $825^{\circ} \mathrm{C}\left(1.517{ }^{\circ} \mathrm{F}\right)$, sebuah proses yang disebut kalsinasi atau pembakaran-kapur, untuk membebaskan molekul Carbon Dioksida (CO2); meninggalkan kapurmentah. Kapur ini tidak stabil dan, ketika didinginkan, secara spontan akan bereaksi dengan $\mathrm{CO} 2$ dari udara sampai, setelah cukup waktu, itu akan benar-benar diubah kembali menjadi Calsium Carbonat kecuali dipuaskan dengan air untuk ditetapkan sebagai kapur plester.

Kapur mentah menghasilkan energi panas dengan pembentukan hidrat, kalsium hidroksida, dengan persamaan sebagai berikut:

$\mathrm{CaO}(\mathrm{s})+\mathrm{H} 2 \mathrm{O}(\mathrm{l})=\mathrm{Ca}(\mathrm{OH}) 2(\mathrm{aq})$

$(\Delta \mathrm{Hr}=-63.7 \mathrm{~kJ} / \mathrm{mol} \mathrm{CaO})$

Achmad Fatkhurrozi, Dewi Patonah, Jamari Machmudin 
Seperti hidrat, sebuah hasil reaksi eksotermis dan zat padat membengkak. Hidrat dapat diubah menjadi kapurmentah dengan menghilangkan air dengan memanaskannyasampai kemerahan untuk membalikkan reaksi hidrasi. Satu liter air yang bergabung dengan sekitar 3,1 kilogram $(6,8 \mathrm{lb})$ dari kapur untuk memberikan kalsium hidroksida ditambah 3,54 MJ energi. Proses ini dapat digunakan untuk menyediakan sumber panas portabel nyaman, seperti untuk pemanasan makanan dengan segera dalamtempat pemanasan sendiri.

Karena itu produk jadi Calsium Oksida harus di hindar kan kontak denga udara terlalu lama karna udara mengandung $\mathrm{CO}_{2}$ yang dapat mengkotaminasi $\mathrm{CaO}$ menjadi $\mathrm{CaCO} 3 \mathrm{Calsium}$ Oksida berguna ketika Masih menjadi $\mathrm{CaO}$.

Packing yang di gunakan adalah bahan Packing yang berukuran besar dan tidak memiliki rongga udara sedikit pun $\mathrm{CaO}$ biasa di jual si pasaran berbentuk serbuk yang berukuran Mesh cara penjualan sering dilakukan dengan menggunakan truck tabung besar (HI - BLOW) dan juga biasa juga di pesan dalam Packing Jumbo Bag.

\section{AnAlisis dan Perancangan}

Masalah yang di alami PT.SIBELCO Bhumiadya adalah penurunan kualitas yang terjadi di karenakan produk terlalu lama kontak dengan udara, bisa di sebabkan karena beberapa hal yaitu :

1. Desain gudang yang kurang menjaga produk dari kontak udara

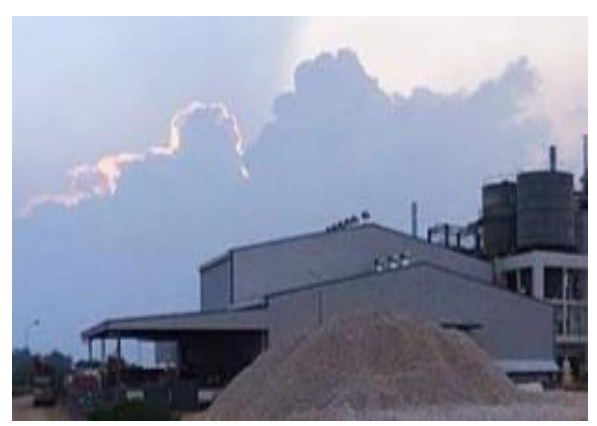

Gambar 3 Gudang PT.SIBELCO Bhumiadya

Dilihat dari desain gudang yang dimana menggunakan dinding berbahan baja tipis berbentuk seperti seng memiliki gelombang yang menyebabkan udara masuk dari rongga rongga ujung baja tipis yang berongga, sebaiknya desain gudang di ganti dengan menggunakan tembok beton di diding dan di atap dan di beri lubang udara kecil secukupnya untuk bernafas dikarenakan jarang pekerjaan yang melibatkan orang di dalam gudang di karenakan proses sudah menggunakan full otomatis dan diberi himbauan kepada pegawai untuk tidak bekerja terlalu lama di gudang di karena kan kurang nya udara.

Mengunakan layout gudang dengan sitim arus lurus sehingga barang yang pertama masuk di keluarkan telebih dahulu di simpan dekat dengan loading bay.

2. Desain packing yang kurang menjaga produk dari kontak udara

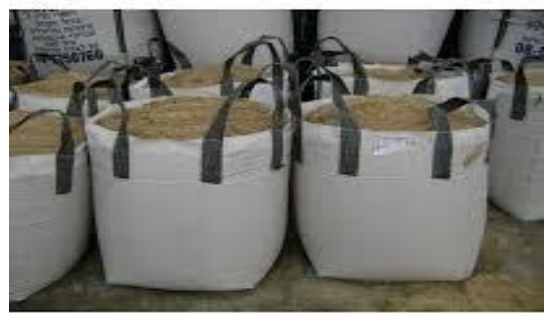

Gambar 4 Jumbo Bag PT.SIBELCO Bhumiadya

\section{Sistem keluar masuk Barang}

Dalam hal ini perlu di lakukan nya penelitian seperti berapa penurunan kualitas Calsium Oksida dalam setiap periode nya. Supaya menjadi penentuan berapa banyak barang yang harus di packing per periode nya dan berapa banyak barang yang keluar per periode nya untuk memenuhi permintaan per bulan karna permintaan dalam usaha di bidang ini biasa nya permintaan yang harus di penuhi dalam jangka waktu per bulan dan ada juga permintaan dadakan yang biasa nya di kirim langsung menggunakan truck bertabung.

Hasil data penelitian Laboratorium Qualitas penetuan kada $\mathrm{CaO}(\%)$

Tabel III.1 Hasil kadar CaO

\begin{tabular}{|c|c|c|c|}
\hline Hari ke & Kualitas awal & Kualitas akibat penyimpanan & penurunan \\
\hline 1 & \multirow{7}{*}{$q^{3^{0}}$} & 92.00 & 0.30 \\
\hline 2 & & 91.20 & 0.80 \\
\hline 3 & & 90.66 & 0.54 \\
\hline 4 & & 90.00 & 0.66 \\
\hline 5 & & 89.63 & 0.37 \\
\hline 6 & & 88.20 & 1.43 \\
\hline 7 & & 88.00 & 0.20 \\
\hline & & rata rata penurnan & 0.61 \\
\hline
\end{tabular}




\section{KESIMPULAN DAN SARAN}

Dari data pengamatan gudang PT.SIBELCO Bhumiadya di dapat beberpa kesalahan desain gudang, tata cara penyimpanan produk dan sistem keluar masuk yang haus di perbaiki. (1) Desain dinding gudang yang menggunakan bahan sebagian beton dan di tutupi dengan dinding baja tipis yang di mana di temukan nya banyak rongga rongga udara di ujung baja dan bentuk baja rang mempunyai gelombang seperti seng yang menyebabkan udara masuk, layout gudang dimana penyimpanan barang masuk dan keluar kurang mengikuti sitem dimana masih kurang di atur. Disarankan untuk merubah disain didin dan atap gudang menggunakan beton supaya minim nya udara masuk dan perubahan sistem layout gudang agar barng yang masuk pertama keluar pertama juga dengan menggunakab sitem layout gudang lurus dimana barang masuk pertama di simpan di dekat loading bay. (2) Desain packing yang di gunakan menggunakan jumbo bag yang tidak tertutup di bagian atas. Disarankan untuk mendisain jumbo bag khusus yang tertutup di seluruh bagian atau di gunakan jumbo bag yang memiliki tutup ikatan atas nya. (3) Sitem keluar masuk barang, standar produk perusahaan > $89 \%$, dari hasil penelitian Quality Control kualitas produksi $92.30 \%$, dari hasil penelitian penyimpanan di setiap periode nya di dapat kan rata rata pengurangan $0.61 \%$, dari hasil penyimpanan tersebut di dapatkan bahwa penyimpanan tidak boleh melebihi 5 hari. Disarankan untuk petugas warehouse, produksi dan marketing untuk berkordinasi supaya penyimpanan tidak melebihi 5 hari dam kualitas produk tetap terjaga sampai ke customer.

\section{REFERENSI}

Donal J, Bowersox. (2000). Managemen Logistik jilid 1, Penerbit Bumi Aksara, Yogyakarta

Undang Undang Republik Indonesia (1962). Perusahaan daerah, PERPU No 5

Warman, John. (2004). Manajemen Pergufangan, Pustaka sinar harapan, Jakarta

Haynes, William M., ed. (2011). CRC Handbook of Chemistry and Physics (92nd ed.). CRC Press. 